\title{
ECRS's Principles for a Drinking Water Production Plant.
}

\author{
Klorklear Wajanawichakon $^{1 *}$ and Chet Srimitee ${ }^{2}$ \\ Department of Industrial Management Technology, \\ Faculty of Industrial Technology, Ubon Ratchathani Rajabhat University \\ Ubonratchathani, Thailand,
}

\begin{abstract}
In this paper, we are going to demonstrate efficient ways on how to improve the production of safe drinking water at a plant by the theory Method, Study and Work Measurement. We studied the production methods, motion and time of the operator and analyzed the process flow charts. We eliminated the unnecessary collection in the operating system and some of the other activities to reduce the time and labor to increase the productivity per hour. Along with the method study we also implemented and used customized jigs and fixtures to hold, locate and guide the product in the bottle neck manufacture. With these findings we were able to create new working practices in the water treatment plant which resulted in a $50 \%$ increase in output to conventional production methods. The Experiment proved that functional analysis and improvements to the existing system were more effective than the traditional methods.
\end{abstract}

Keywords: ECRS's principle, Standard Time.

\section{Introduction}

Water is an important factor in the lives of human beings. However, due to the natural environment has changed. Natural water in rivers or the environment contaminants could not be like a past. There are currently producing bottled water sold in bulk and products that have become necessary. Flooding of the central region of Thailand, the cause of drinking water in shortage supply. The factory could not produce bottled water. From the origin and significance of the problems mentioned above. The research team realizes the importance of solving the problem. We started studying the issue of bottled water production plant, located in the area of the university, which has its own logo. This plant has two water bottle size is $350 \mathrm{ml}$ and the second is $600 \mathrm{ml}$, respectively.

In this paper, we consider and apply work method and work measurement to improve motion and time study in production process which is the bottle neck station. We implement jig and fixture to support work in process and certainly, it can reduce the processing time is greatly and make it more productive.

\section{Theory and Literature Review:}

Theory of Frederick W.Taylor(1856 - 1915), who pioneered the technique of the study (Time Study) to take seriously, which determine the appropriate amount of the employee should be done and provide tools for the job. The analysis process in detail and divided into tasks, then the timer. The results found that Taylor can reduce wasting time and increasing more productivity. Afterwards, Frank B. Gilbreth (1868-1924) and Lilian M. Gilbreth (1878-1972) initiated motion and time study by analyzing the movement of people in the work, cut out unnecessary movement so that the movement more effective and reduce fatigue in the work for less by tool which call Flow Process Chart. After that the work study has been adopted in diverse industries. The Work Study consisted of two techniques, 1. Method Study is the process of subjecting work to systematic, critical scrutiny to make it more effective and/or more efficient. It is one of the keys to achieving productivity improvement. 2 . Work Measurement is a term which covers several different ways of finding out how long a job or part of a job should take to complete. It can be defined as the systematic determination, through the use of various techniques, of the amount of effective physical and mental work in terms of work units in a specified task. The work units usually are given in standard minutes or standard hours.

\subsection{Standard Time.}

Standard Time is a unit of work measurement, the sum of the normal time and allowance. The normal time calculated from average time of subtasks multiply with penalty rate. While the allowance was divided into three categories such as personal allowance, Allowance of stress and allowance of the delay.

\subsection{Principles of ECRS.}

ECRS's principles consist of the Eliminate, Combine, Rearrange, and Simplify which is a simple way to reduce losses as well.

1. Eliminate is a consider how the current work and eliminate waste of seven was found in manufacture such as the delay, Removing unnecessary, functions that are not beneficial, and waste.

2. Combine: It works by reducing the unnecessary step bunching together, reduce process down and production is faster. The movement during the process down.

3. Rearrange: What is the process to reduce unnecessary movement or delay between process. For the example, we swap step 2 and step 3 for reducing distance moving.

4. Simplify: For improving the work easier, more convenient. Sometime we design jig and fixture to help for the convenience and accuracy. Of the above, we conclude that there are several ways to reduce work time by dint of ECRS technique, motion and time 
study, line balancing, and activity analysis etc.

\section{Research Methodology.}

\subsection{Basic Information.}

We started from observation the activity in process and classification activity following:

Table 1 Activity and average time.(Before)

\begin{tabular}{|l|c|}
\hline \multicolumn{1}{|c|}{ Activity } & Average Time. \\
\hline 1. Washing bottles. & 3.15 \\
\hline 2. Placing the bottle on a box. & 2.46 \\
\hline 3. Filling the water. & 3.27 \\
\hline 4. Closing the lid and turning. & 2.23 \\
\hline 6. Placing the bottle on a tray. & 8.28 \\
\hline 7. Filming/ Film blowing. & 6.72 \\
\hline 8. Packing plastic. & 18.78 \\
\hline Total & 44.89 \\
\hline
\end{tabular}

The factory plant has 2 production scales. We found that the $600 \mathrm{ml}$ has a package of 12 bottles/Pack and the $350 \mathrm{ml}$ has a package of 16 bottles/Pack as a following Fig. 1

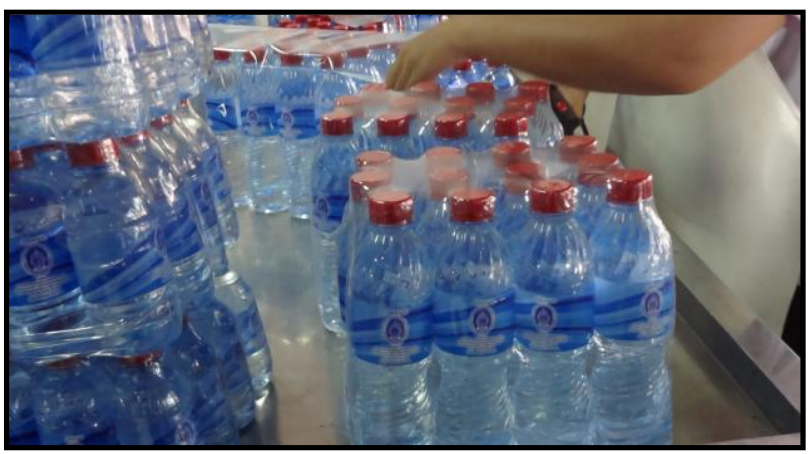

Fig. 1 The characteristic of products.

Fig. 2 Fish bone diagram.

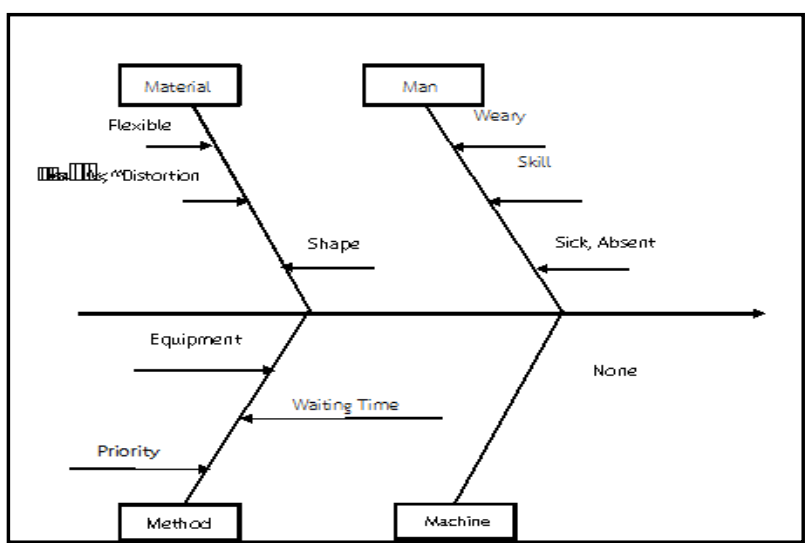

We search for the source of problem by using fish bone diagram by organizing the criteria into 4 criteria which are Material, Man, Machine and Method as following Fig. 2
By analyzing the fish bone diagram we found that the placing process is a bottle neck of the production process because the process take time to full up the tray therefore it is a waste of time and motion. Since the problem was found we come up with the solution by using flow process chart as the following Fig. 3 and we found that there is one waiting process that cause the time wasting.

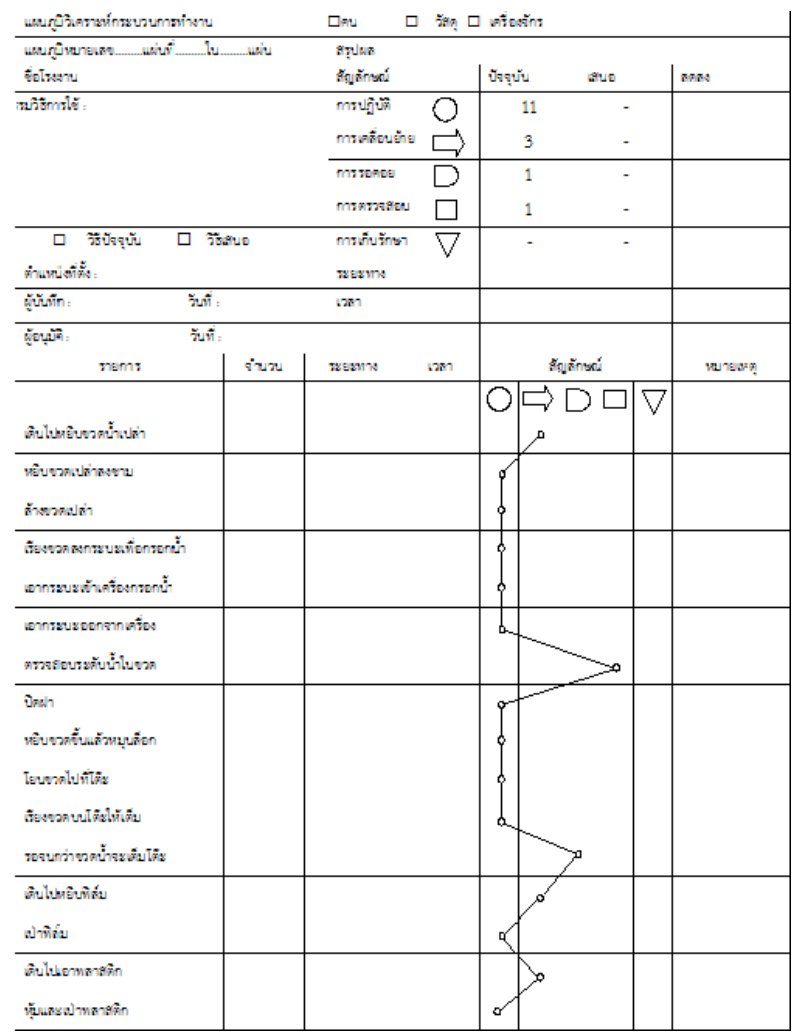

Fig. 3 Flow Process Chart before take equipment.

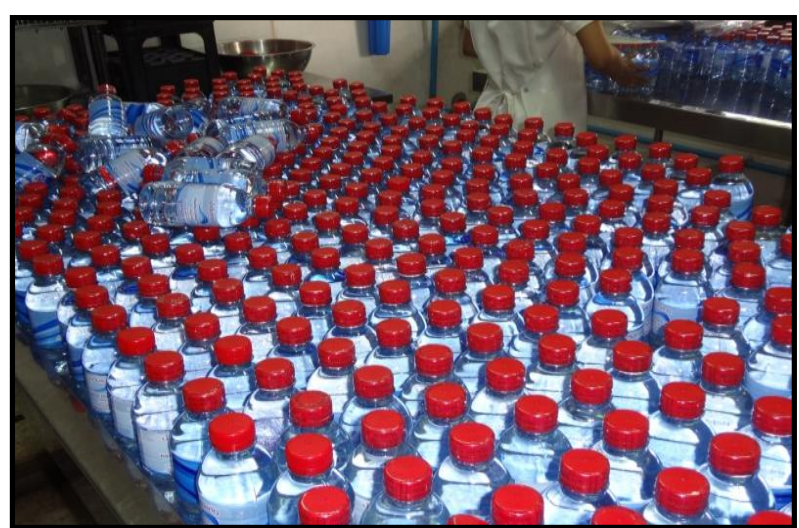

Fig. 4 Display placing process on the tray.

And in Fig. 4 as showing the placing process on the tray. 


\subsection{Methodology.}

After the research analysis we found that the major problem of the process was caused by the process that is not effective enough so that we implement the equipment to help reducing the time wasting as following Fig. 5

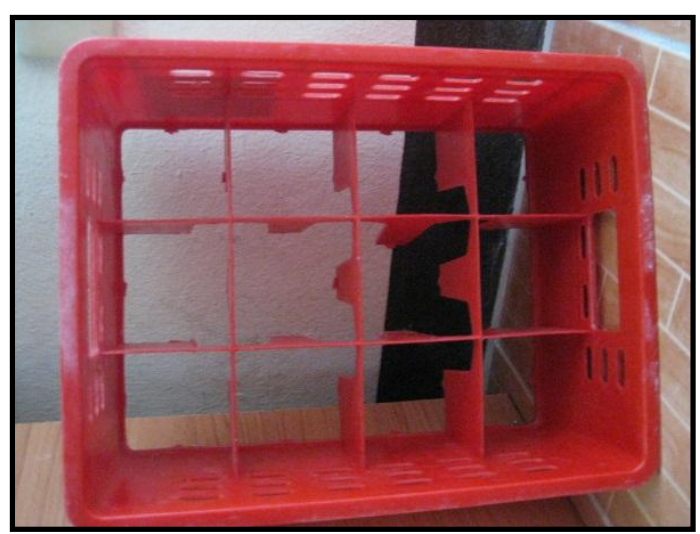

Fig. 5 The equipment is rack.

From the Fig. 5, we display the rack to help in placing process which the bottom of the rack is cut off after the operator close the lid, lock the bottle. The bottles will be put in the equipment by the operators instead of the old placing process. The new process will help the operators who are in charge off framing to easily put the film on the bottle without being confused. After the filming process, the operators could lift up rack out of the bottles transfer to the packaging process as following Fig. 6

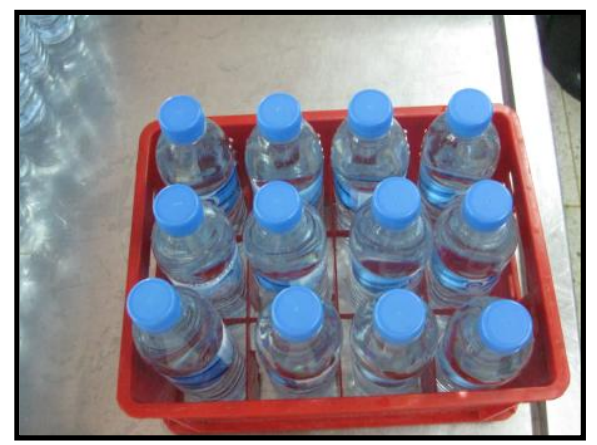

Fig. 6 Bottles on rack.

After that we used flow process chart to compare the activities before and after using the equipment as following Fig. 7

\begin{tabular}{|l|c|}
\hline \multicolumn{2}{|c|}{ Symbol } \\
\hline Operation \\
\hline Transfer
\end{tabular}

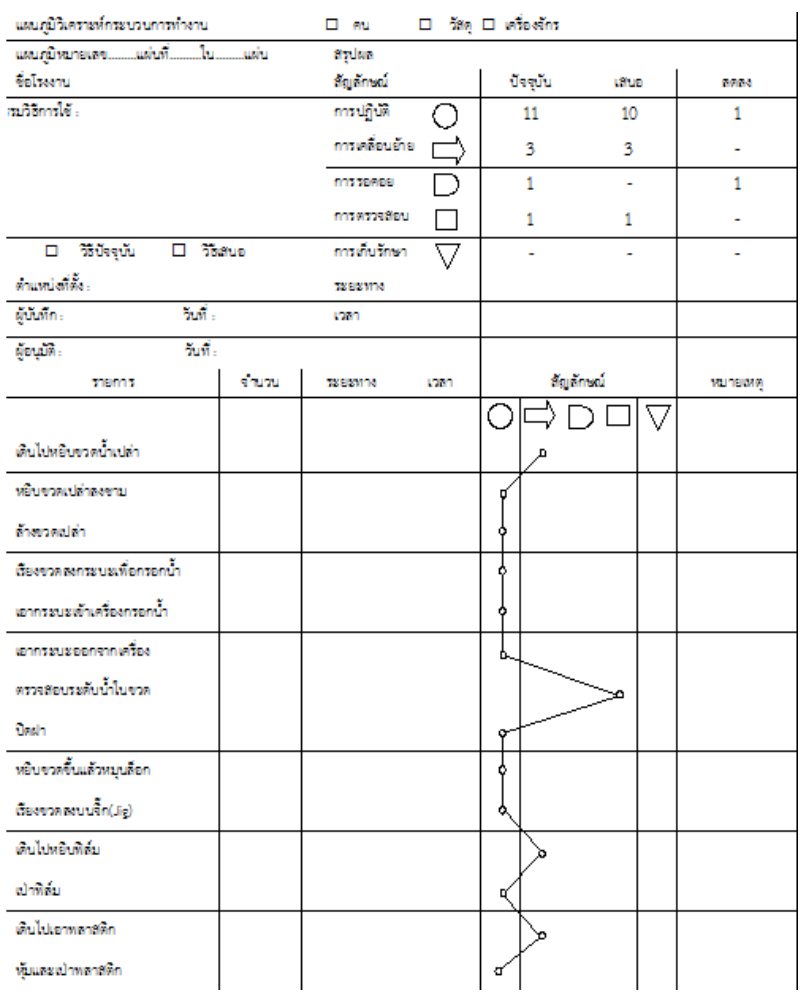

Fig. 7 Flow Process Chart after take equipment.

\begin{tabular}{|ll|c|}
\hline \multicolumn{2}{|c|}{ Symbol } & Activity \\
\hline Operation & 10 \\
\hline Transfer & \\
\hline Delay & 3 \\
\hline Inspection & - \\
\hline
\end{tabular}

After applying the equipment into the process, it shows that the equipment reduce the time consuming in waiting process that cause the process to be more effective. The confusion is not found by the operators in placing and filming process. The bottles are well placed in order which made them easy to be packaged. 


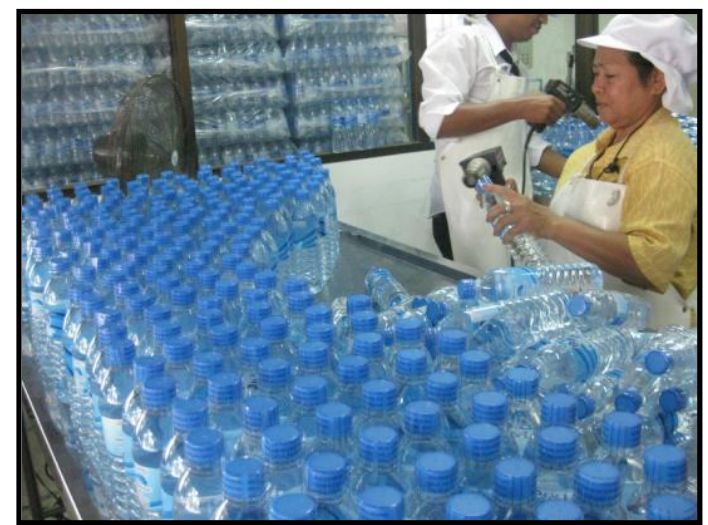

Fig. 8 Filming Activity.

Table 2 Activity and average time. (After)

\begin{tabular}{|l|c|}
\hline \multicolumn{1}{|c|}{ Activity } & $\begin{array}{c}\text { Average } \\
\text { Time. }\end{array}$ \\
\hline 1. Washing bottles. & 2.95 \\
\hline 2. Placing the bottle on a box. & 2.45 \\
\hline 3. Filling the water. & 3.26 \\
\hline 4. Closing the lid and turning. & 2.22 \\
\hline 6. Placing the bottle on a tray. & 2.34 \\
\hline 7. Filming/ Film blowing. & 2.37 \\
\hline 8. Packing plastic. & 14.06 \\
\hline Total & 29.65 \\
\hline
\end{tabular}

We calculated the average time using in every process. We found that after applying the equipment, the average time has been reduced from the process that was used before the equipment was applied.

When we calculated for standard time using the normal time under the condition of allowance time is 20 percent of the normal time and defy that the rating equals to 100 . The differences are as follow formulation which standard time (Std.) equal to:

Normal Time+(Normal Time*(\%Allowance Time $))$
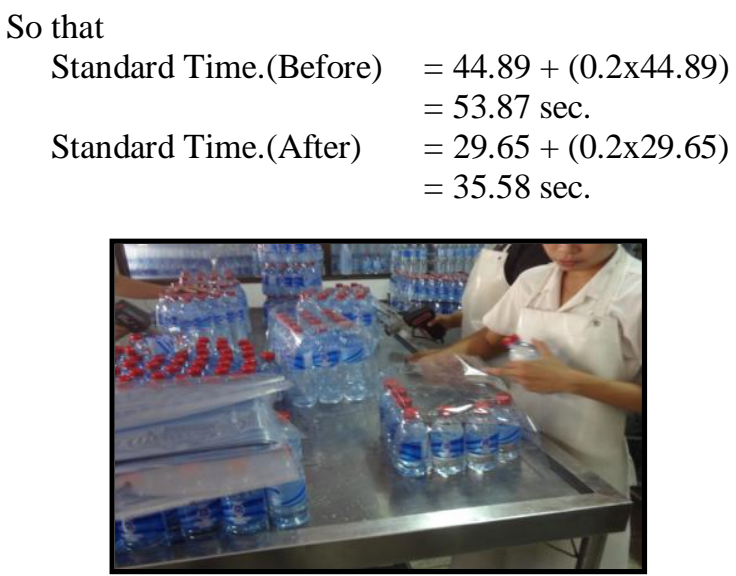

Fig. 9 Packaging Activity.

\section{Results}

When we considered cycle time before and after, the results was shown as following:

Normal Time. $($ Before) $=44.89 \mathrm{sec} . / \mathrm{pcs}$. And productivity is $80 \mathrm{pcs} . /$ hour.

Normal Time. $($ After) $=29.65 \mathrm{sec} . / \mathrm{pcs}$. And productivity is $120 \mathrm{pcs}$./hour.

The results had shown that new equipment, more efficient way of sharing the work.



Fig. 10 Packaging Activity $600 \mathrm{ml}$.

\section{Conclusion}

After applying the equipment, the process using the in factory plant, we found that the equipment has an ability to reduce the reasonable number of cycle time using in the process. The factory gains 50 more percent of productivity from the old process therefore the conclusion is that the new process has been proven to be more effective than the old one.

The suggestion is that the operators who are in the production process should be full time employee since the full time employee will be more skillful that would cause the productivity rate to be stable.

\section{Acknowledgement}

This work was supported by the department of Industrial Management Technology in the Faculty of Industrial Technology at Ubon Ratchathani Rajabhat University.

\section{References}

[1] Lowry,S.M. Maynard H.B., and Stegemerten. G.J., "Time and Motion Study and Formulas for Wage Incentives", NY: McGraw-Hill., 3 rd ed., 1940

[2] Barnes, Ralph M., "Motion and Time Study : Design and Measurement of Work", NY:John Wiley \& Sons., 7 ed., 1980

[3] Sink, D.S., "Productivity management planning Measurement and evaluation control and Improvement", United state of America: John Wiley and son, inc.

[4] Barbiroli, G., "The utilization rate and value of goods as strategic factors in resource productivity and development", Journal of cleaner Production, Vol. 
14,2005 .

[5] Paul H.P., Yeow and Rabindra NathSen., "Productivity and quality improvement revenue increment and rejection cost induction in the manual component insertion lines through the application of ergonomic, International journal of Industrial Ergonomics, Vol. 36, pp. 367 - 377., 2006.

[6] Escopizo R., "Understanding work productivity and its application to work - related musculoskeletal disorders, International journal of Industrial Ergonomics, N.p., 2007.

[7] Ferguson, David S., "Don't call it Time and Motion Study"., IIT Solution., Norcross., Vol. 29, Issue 5., 1997.

[8] Finkler, Steven A., A comparison of work sampling and time-and-motion techniques for studies in health service research., Health service research., Chicago., Vol. 28, Issue 5., 1993.

[9] Koehler., Kenneth G., "Time Cost Analysis"., CMA., Hamiton., Vol. 66, Issue 4., 1992.

[10] Russell, Roberta; Taylor Bernard W., "Operation Management”., Prentice Hall inc., Upper saddle river., N.J., 2000.

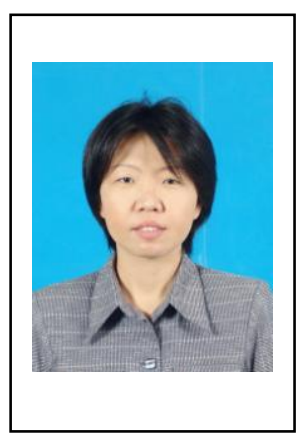

\section{Klorklear Wajanawichakon}

is a professor of Faculty of

Industrial Technology at Ubon Ratchathani Rajabhat University. She received her Ph.D. degree in Industrial Engineering from Ubon Ratchathani University in 2009. Her Research interests are in area of metaheuristic and Supply chain management. 